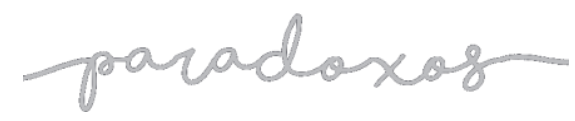

\title{
Educação como Prática de Liberdade
}

\author{
Education as a Practice of Freedom
}

\section{La Educación como Práctica de Libertad}

\author{
Ricael Spirandeli Rocha \\ Instituto Federal de Educação, Ciência e Tecnologia do Triângulo Mineiro - MG - Brasil \\ ORCID: https://orcid.org/0000-0003-3190-7513 \\ Endereço Currículo Plataforma Lattes: http://lattes.cnpq.br/1404009779475100 \\ E-mail: ricael.rocha@estudante.iftm.edu.br
}

Resumo: A presente resenha destaca pensamentos e ideias da obra Educação como Prática de Liberdade, escrita em 1967 pelo educador e filósofo Paulo Freire, considerado o patrono da educação brasileira. Freire apresenta o método de conscientização inserido na alfabetização de adultos que o educador adotou, não foi uma repetição pedagógica ou a entrega de um conjunto de letras e sim, uma alfabetização que havia cultura, poesia, criação, diálogo, criticidade e consciência, com o intuito de realizar a transformação libertadora que o autor sempre acreditou. Além disso, a obra destaca toda opressão que singulariza as massas, sabiamente compreendia a necessidade de encontrar com os oprimidos, emergir a criticidade que cada um deveria despertar em si, proveniente da educação. Desse modo, Freire apostou em uma educação que despertasse a reflexão do homem, que trouxesse a conscientização do ser e libertasse de forma integral suas ações para uma sociedade aberta a partir de uma alfabetização que transforma a vida daquele que outrora não conhecia o universo pedagógico, assumindo assim, sua realidade, essência e existência social a partir da Educação de Adultos, que buscou a reduzir drasticamente o analfabetismo.

Palavras-chave: Educação. Liberdade. Pedagogia.

\begin{abstract}
The present review highlights thoughts and ideas from the work Education as a Practice of Freedom, written in 1967 by the educator and philosopher Paulo Freire, considered the patron of Brazilian education. Freire presents the method of conscientization inserted in the adult literacy that the educator adopted, which was not a pedagogical repetition or the delivery of a set of letters, but rather,
\end{abstract}




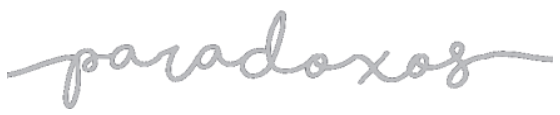

Educação como

prática de liberdade

ROCHA, 2021

a literacy that had culture, poetry, creation, dialogue, criticality, and awareness, with the aim of achieving the liberating transformation that the author always believed in. Furthermore, the work highlights all the oppression that singularizes the masses, wisely understood the need to meet with the oppressed, to emerge the criticality that each one should awaken in himself, coming from education. In this way, Freire bet on an education that would awaken man's reflection, that would bring about the conscientization of the being and would fully liberate his actions for an open society based on a literacy that transforms the life of the one who, in the past, did not know the pedagogical universe, thus assuming his reality, essence and social existence based on Adult Education, which sought to drastically reduce illiteracy.

Keywords: Education. Freedom. Pedagogy.

Resumen: La presente reseña destaca pensamientos e ideas de la obra La educación como práctica de la libertad, escrita en 1967 por el educador y filósofo Paulo Freire, considerado el patrón de la educación brasileña. Freire presenta el método de concientización insertado en la alfabetización de adultos que el educador adoptó, no era una repetición pedagógica o la entrega de un conjunto de letras y sí, una alfabetización que tenía cultura, poesía, creación, diálogo, criticidad y conciencia, para llevar a cabo la transformación liberadora que el autor siempre creyó. Además, la obra pone de manifiesto toda la opresión que singulariza a las masas, entendiendo sabiamente la necesidad de encontrarse con los oprimidos, para que surja la criticidad que cada uno debe despertar en sí mismo, procedente de la educación. De este modo, Freire apostó por una educación que despertara la reflexión del hombre, que hiciera tomar conciencia del ser y liberara plenamente sus acciones para una sociedad abierta basada en una alfabetización que transformara la vida de quien antes desconocía el universo pedagógico, asumiendo así su realidad, esencia y existencia social a partir de la Educación de Adultos, que buscaba reducir drásticamente el analfabetismo.

Palavras-clave: Educación. Libertad. Pedagogía.

A educação é um ato de amor, por isso, um ato de coragem.

FREIRE, 2019, p. 97.

Educação como Prática da Liberdade é uma obra escrita em 1967 pelo educador e filósofo Paulo Freire. Distribuída pela editora Paz \& Terra, o livro possui 192 páginas, publicada em 2 de dezembro de 2019. A obra inicia com uma reflexão sociológica sobre pedagogia da Liberdade no contexto da Educação e Política, escrita por Francisco C. 


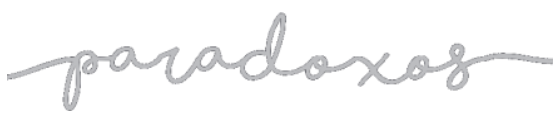

Educação como

prática de liberdade

ROCHA, 2021

Weffort. Em seguida, Thiago de Mello nos contempla com uma poesia - Canção para os Fonemas da Alegria, escrita em Santiago do Chile no verão de 1964.

O livro possui quatro capítulos, o primeiro aborda - A Sociedade em Transição, trazendo ao leitor uma introdução sobre como a sociedade brasileira estava sob uma travessia política. No segundo capítulo, Freire aborda o conceito de Sociedade Fechada e Inexperiência Democrática, destacando o quanto o povo brasileiro ainda era inexperiente quanto aos conceitos da democracia, vivenciando uma sociedade fechada desde a colonização do país. No terceiro capítulo o autor traz uma comparação entre Educação e Massificação, apontando o quanto o fator educacional transforma o ser humano, conscientiza e liberta. Por fim, no quarto e último capítulo, Freire destaca seu método a partir da Educação e Conscientização, mostrando a importância de educar e conscientizar o sujeito, para além da sala de aula sob uma perspectiva crítica que possui raízes histórico-culturais e que consiga dialogar com todas as classes sociais.

O primeiro capítulo da obra - A Sociedade Brasileira em Transição; Paulo Freire inicia o conceito de relações, ao qual aponta que o homem possui características particulares que o distingue dos demais animais. $\mathrm{O}$ autor enceta um discurso ontológico refletindo que o homem não possui uma padronização de respostas para as perguntas, alterando o ato de responder, organizando-se a escolher a melhor respostas para mais diversas perguntas. Isto é, o homem sob suas relações, estabelece um contato com o mundo a partir de uma própria pluralidade advindo de sua individualidade, estabelecendo um domínio que é exclusivamente cultural e histórico.

A partir dessa premissa, Freire destaca que o animal é um ser que se acomoda e se ajusta devido suas necessidades, já o homem, realiza sua integração social, fazendo-se homem de acordo com suas necessidades, lutando sempre por sua própria humanização a partir de ameaças sofridas pela opressão dolorosa que ocorre na sociedade, em busca de auto libertar-se. Desse modo, o homem busca a partir das relações com a realidade, criar ações que ele decide e recria, conectando-se com épocas remotas da história do próprio sujeito, a partir disso, o homem consegue decidindo suas etapas e participando de sua própria história, fazendo melhor a cada vez que integra-se como suas próprias tarefas.

DOI: http://doi.org/10.14393/par-v6n1-2021-60652 - Paradoxos, Uberlândia, v. 6, n. 1, p. 176-182, jan./jun. $2021 \mid 178$ 


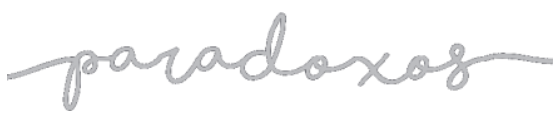

Educação como prática de liberdade

Todo esse argumento parece ser inóculo e simples, contudo, Freire aponta que "o homem moderno está esmagado por um profundo sentimento de impotência que o faz olhar fixamente e, como que paralisado, para as catástrofes se avizinham" (FREIRE, 2019, p. 43). Nessa conjuntura, surge a necessidade de criar-se uma atitude crítica e permanente, afirmando-se como sujeito que gera suas ações, desconstruindo a acomodação e a resolução de tarefas impostas pela sociedade aos quais, algumas classes como a elite, não constroem nenhum tipo de diálogo com as massas trabalhadoras, se não, aquelas que correspondem ao fazer e obedecer, resultando como tarefa opressora na denominação de uma "sociedade fechada".

Ao pensar nesse tipo de sociedade, o filósofo relata que: "Na sociedade fechada, temas como democracia, participação popular, liberdade, propriedade, autoridade, educação e muitos outros, de que decorriam tarefas específicas, tinham uma tônica e uma significação que já não satisfazem à Sociedade em trânsito" (FREIRE, 2019, p. 54, grifo do autor). O que Freire destaca é a preocupação de uma liberdade que almejava uma "sociedade aberta", mas, que fosse consciente e crítica de suas ações. Sob esse fator, o autor salienta que naquela atualidade brasileira, o fanatismo separava os homens, gerando ódio que nutriam da irracionalidade consequentemente chegando ao Golpe Militar de 1964. Outrossim, talvez Freire não imaginasse que cinquenta e quatro anos depois do golpe citado, outro golpe iria ser realizado em âmbito nacional e que dois anos depois, o mesmo sentimento de ódio e fanatismo iria engatilhar a elite a eleger a opressão e alienação da sociedade brasileira.

A partir desse ímpeto, Freire destaca toda opressão que singulariza as massas, sabiamente compreendia a necessidade de encontrar com os oprimidos emergir a criticidade que cada um deveria despertar em si, proveniente da educação, mas "por uma educação que, por ser educação, haveria de ser corajosa, propondo ao povo a reflexão sobre si mesmo, sobre seu tempo, sobre suas responsabilidades, sobre seu papel no novo clima cultural da época de transição" (FREIRE, 2019, p. 64).

No segundo capítulo - Sociedade Fechada e Inexperiência Democrática, o autor continua dialogando, analisando a sociedade brasileira, apontando o esvaziamento e perversão que emergia sob uma sociedade "fechada" e antidemocrática. Freire recorda que o Brasil foi marcado por uma colonização predatória, que foi explorado de forma 
econômica, dominado pelos "senhores" tanto de forma material como social a partir de trabalho escravo por nativos e africanos.

A partir desse princípio, pode-se dizer que as classes menos abastadas do nosso país, sempre viveram a inexperiência da política sobre a opressão daqueles que dominavam discursos predadores sob a pretensão da propriedade material. Freire focaliza que a sociedade brasileira se negou a dialogar visto que "não há realmente, como se possa pensar em dialogação com a estrutura do grande domínio, [...]. A dialogação implica numa mentalidade que não floresce em áreas fechadas, autarquizadas" (FREIRE, 2019, p. 69).

Infelizmente, o autor salienta uma delicada distância social que ocorria naquela época, e se faz presente atualmente. Mesmo com tantas leis, ainda é visto que o diálogo nem sempre é recíproco, prevalecendo as leis e as determinações que favorecem a elite e oprimem os menos abastados. A partir dessa inexperiência democrática, é visto que a sociedade "fechada" não está disposta a se abrir, dialogar e repensar suas ações, incluindo socialmente todas as classes, de forma integral e humana.

O terceiro capítulo - Educação "Versus" Massificação, o educador salienta que procurou fazer um estudo nos capítulos que antecederam para que assim tivesse respostas no campo educacional e pedagógicos, sobre as condições educacionais no país. Diante disso, o próprio autor faz uma indagação reflexiva: “Como aprender a discutir e a debater com uma educação que impõe?” (FREIRE, 2019, p. 97).

Ao responder à indagação realizada por Freire, o educador insere pensamento da educação crítica, ou seja, uma forma de educar que alfabetiza o sujeito e transforma suas ações, rompendo a opressão vivida dentro de si mesmo, ou seja, somente assim discutir, debater e dialogar seria possível com uma educação que coage o sujeito. Freire acreditava em uma educação para além da sala de aula, que fosse consciente, pois, somente assim a massa oprimida poderia ter capacidade e condições de resistir à opressão e transitar em direção a racionalidade.

À vista disso, Paulo Freire reafirma que o educador precisa ter condições no agir sob a educação, uma vez que estes ensejos, faltaram nas memórias passadas no contexto histórico-cultural, então a educação deve estar sobre uma ação social que transforma e incorpora nos hábitos do povo brasileiro, uma educação crítica e consciente. As massas dominantes nunca se importaram em instruir, educar e libertar as classes não 


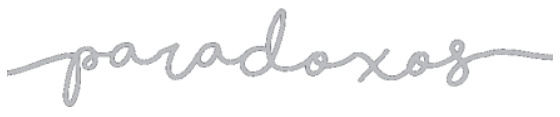

Educação como

prática de liberdade

ROCHA, 2021

alfabetizadas, contudo, esse aprisionamento ocorria pelo fator opressor, em que a falta da conduta democrática atingisse as classes humildes, de forma empoderada e declarada.

No quarto e último capítulo, Freire destaca - Educação e Conscientização. O referido autor mostra sua preocupação em alfabetizar e conscientizar grupos de pessoas que não tinham acesso à escola. O educador conhece as limitações que a educação carrega consigo, Paulo Freire possuía experiencia na educação de adultos, coordenando projeto voltado para essa modalidade, dedicando-se às classes proletarizadas e subproletariadas em alfabetizar e libertar seus alunos.

Como já foi destacado, Freire sempre foi adepto ao diálogo, por isso, uma das primeiras medidas a serem inseridas no grupo de alfabetização foi o debate. Esses eram realizados com assuntos extraídos das próprias entrevistas que eram preparadas com os estudantes. O grupo coordenado por Freire pensava "numa alfabetização direta e realmente ligada à democratização da cultura, que fosse uma introdução a esta democratização" (FREIRE, 2019, p. 104).

O autor tentava inserir uma educação que estava de acordo com a realidade e cotidiano dos alunos, mas que assim, possibilitasse uma alfabetização crítica de cada sujeito, a partir do debate, desafios e conscientização, para que assim, houvesse a liberdade de dentro de si, que conseguisse dialogar e modificar a ação na sociedade.

Freire em seu método dividiu em cinco partes diferentes, ao qual consistia em: $1^{\circ}$ ) levantar o universo de palavras dos grupos que se trabalhava; $2^{\circ}$ ) escolher as palavras daquele universo, ou seja, selecionar o vocabulário pesquisado; $3^{\circ}$ ) criar situações reais que existiam no cotidiano dos grupos aos quais estavam sendo trabalhados; $4^{\circ}$ ) elaborar fichas/roteiros que auxiliavam os coordenadores do debate quando trabalhavam com a turma; $5^{\circ}$ ) criação das fichas com decomposição das famílias fonéticas que correspondiam as palavras geradores.

O livro "Educação como Prática de Liberdade" não é apenas uma obra de Paulo Freire, mas, um convite a refletir sobre as ações que o docente pode tomar para conscientizar seus alunos, fazer uma pedagogia libertadora que possa levar até os alunos diálogo, ação e criticidade de seus compromissos que integram o cotidiano. Recomenda-se a leitura na íntegra dessa fabulosa obra, e mais do que isso, que todas os pontos levantados em cada capítulo, sirva de inspiração para sociedade, sendo estes, docentes ou não pois a luta pela liberdade é continua, tanto 


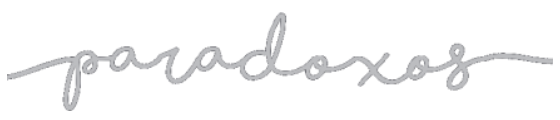

Educação como prática de liberdade

para o professor que liberta a si mesmo, quanto para o aluno que é libertado das opressões que as sociedades impõem, a partir de leis que nem sempre incluem todas as classes e protegem os menos favorecidos.

Por fim, Freire acreditou e inseriu uma educação transformadora, em tempos que a tecnologia digital não existia nas casas dos alfabetizandos, contudo, no atual momento, a tecnologia transformou-se em uma ferramenta que pode auxiliar na educação dos alunos, cabe ao educador e ao educando utilizar seus métodos e se conscientizar, assim como Freire fez, para nos libertarmos das amarras opressoras.

\section{Referências}

FREIRE, Paulo. Educação como prática da liberdade. 1. Ed. - São Paulo: Paz e Terra, 2019. 